\title{
Approaches to learning of chinese nursing students: cross-sectional study
}

\begin{abstract}
Due to the substantial nursing shortage in Hong Kong, hospital-based nurse training emerged again since 2008 as one of the major sources of nurse education. It is therefore necessary to explore whether the reopened hospital-based nursing schools can optimize students' learning. To this end, the aim of the study is to investigate approaches to learning adopted by nursing students after completing a higher diploma programme offered by a local hospital. Method: A cross-sectional study comparing the learning approaches of newly admitted students and final year students of Higher Diploma in Nursing Programme at a local hospital in Hong Kong in 2012. 96 first year students and 89 final year students were recruited. They completed the 42 -items Study Process Questionnaires. Descriptive statistics were computed to generate the background information of the respondents and the learning approaches they adopted. Independent $t$ test was used to investigate the difference in learning approach between first year and final year students. Results: Final year students had a significantly lower mean score on deep motive, deep strategic, achieving motive and achieving strategic approaches as compared to those of first year students $(\mathrm{t}=3.9, \mathrm{p}=0.00 ; \mathrm{t}=5.58, \mathrm{p}=0.00$; $\mathrm{t}=2.01, \mathrm{p}=0.046 ; \mathrm{t}=8.38, \mathrm{p}=0.00)$. Conclusion: Final year students were prone to adopt surface approach in their learning. The hospital-based nurse training seems not encouraging students to think deeply.
\end{abstract}

Keywords: learning approaches, nursing education, chinese
Volume 3 Issue 3 - 2017

\author{
Anson Chui Yan Tang \\ Assistant Professor, School of Nursing, Tung Wah College, Hong \\ Kong
}

Correspondence: Anson Chui Yan Tang, Assistant Professor, School of Nursing, Tung Wah College, Hong Kong, Email ansontang@twc.edu.hk

Received: May 23, 2017 | Published: July II, 2017

\section{Background}

The nursing shortage in Hong Kong is as alarming as that in other countries. The ageing trend in the society urges the need to provide more health care services in order to meet the increasing demand. Nurses, being one of the major workforces in health care delivery, become a profession facing substantial manpower shortage. To tackle the issue of the nursing shortage, both public and private hospitals are trying to overcome the shortage by newly launching or reopening hospital-based nursing schools. This movement seems to impede the advancement of the nursing profession as the shutdown of hospitalbased nursing training decades ago aimed to promote the quality of nurses to a higher standard by having all training at tertiary institution and universities. As compared to those nursing programmes at tertiary institutions/universities, hospitals do spend much less resources in nurse training in terms of learning environment, curriculum design, quality of nursing faculties, etc. Having said so, it is important to investigate how these hospital-based nurse training programmes affect students' learning. To this end, the study aimed to investigate the learning approach of nursing students from hospital-based nursing school. The hypothesis is that final year students tend to use deep learning approach as compared to first year students.

\section{Methods}

\section{Study design \& sampling}

It was a cross-sectional study conducted at one of nursing schools at a local public hospital in Hong Kong in 2012. A total of 100 first year students and 100 final year students who enrolled in the Higher Diploma in Nursing Programme were recruited by convenience.

\section{Variables \& instrument}

An approach to learning was measured by the 42-item Study Process
Questionnaire devised by Biggs ${ }^{1}$ This self-reported questionnaire is one of the commonest questionnaires used to assess students' learning approach. It contains 3 main scales: surface, achieving and deep approaches with 2 subscales, motive and strategies under each main scale. The respondents were required to answer the 42 items by indicating the level of agreement on 1-5 point scales. 1 means 'never or rarely true of me' and 5 means 'always or almost always true of me'. The final score in each scale is calculated by summing up the scores on corresponding items of each scale. The internal consistency of the questionnaire is generally satisfactory with most of the scales attaining Cronbach's alpha coefficient of 0.6 or above. And its validity is also satisfactory. ${ }^{1}$

\section{Data collection}

Questionnaires were disseminated to students in class. They were explained the purpose of the study and benefit of the study. It was anonymous and the results did not affect their academic performance. They were free to decide whether returning the questionnaire without penalty. The whole procedure took about 20 minutes. Mean and standard deviation were computed to show the dispersion of the data. Independent $t$ test was used to compare the mean difference of each scale between first year and final year students. P-value less than 0.05 was regarded as statistically significant.

\section{Ethical consideration}

Ethics approval was obtained from the Nursing Research Approval Committee of the hospital. Students were given information sheet and were explained the purpose, potential benefits of the study. Students were free to return the filled questionnaire without penalty. Informed consents were obtained from the students before started filling in the questionnaire. The collected questionnaires were kept in a locked cabinet in the researcher's office. Only the researcher could access to the questionnaires. 


\section{Results}

A total of 185 students filled in and returned the questionnaires. 98 were first year students and 87 were final year students with an average response rate of $92.5 \%$. Age was found to have a significant difference between two groups $(\mathrm{p}=0.000)$ Table 1 .

Table I Age and Gender Distribution of Year I and Final Year Respondents $(\mathrm{N}=185)$

\begin{tabular}{llll}
\hline No. of respondents & Year I & Year 3 \\
\hline & & 98 & 87 \\
\hline \multirow{2}{*}{ Gender } & Male & 16 & 10 \\
& Female & 83 & 77 \\
Age (yrs) & & $20.5(0.24)$ & $22.4(0.18)$ \\
\hline
\end{tabular}

Table 2 shows the mean and standard deviation of each scale in year 1 and final year students. It was found that final year students had a significantly lower score in deep and achieving approaches as compared to those in year 1 students. The mean difference in surface approaches was insignificant ( $\mathrm{p}>0.0 .5$ ) Table 2 .

Table 2 Mean, Standard Deviation of the SPQ scales of both groups and their between-group differences

\begin{tabular}{llll}
\hline SPQ Scales & Year I(n=98) & Year $\mathbf{3 ( n = 8 7 )}$ & $\begin{array}{l}\text { Independent } \mathbf{t} \\
\text { test }(\mathbf{t}, \mathbf{p})\end{array}$ \\
\hline Achieving & & & \\
Motivation & $21.6(4.8)$ & $20.3(4.7)$ & $2.0, .046^{*}$ \\
Strategy & $24.2(3.9)$ & $19.5(3.8)$ & $8.4, .000^{*}$ \\
Deep & & & \\
Motivation & $22.5(4.0)$ & $20.3(3.8)$ & $3.9, .000^{*}$ \\
Strategy & $24.3(4.3)$ & $21.1(3.5)$ & $5.6, .000^{*}$ \\
Surface & & & \\
Motivation & $23.3(4.5)$ & $23.1(4.1)$ & $0.4,>.05$ \\
Strategy & $21.3(3.8)$ & $21.9(3.3)$ & $-1.25,>.05$ \\
\hline
\end{tabular}

*statistically significant

\section{Discussion}

The results rejected the hypothesis stated at the beginning of the study that final year students tend to use deep learning approaches. And the findings concur with other previous studies. ${ }^{2-4}$ Snelgrove found that final year nursing students in baccalaureate or diploma programmes had no distinctive type of learning style. They tended to use surface learning approach. ${ }^{2}$ Cowman found that nursing students got a higher score on meaning and reproducing orientation approaches at the Approaches to Learning Inventory. Also, the higher score at operative learning demonstrated that nursing students did focus on the use of rules and procedures instead of emphasizing deep understanding. ${ }^{3}$ Another study from Thailand ${ }^{4}$ showed that nursing students at nursing college were prone to adopt reproducing approach instead of meaning approach. It implied that they preferred to fulfill the programme requirement by memorizing all required instead of having a deep understanding on the course materials.

Such findings might be explained by the curriculum design in nursing education, the teaching strategies used to adopt in hospitalbased nursing training and the qualification of nurse educators which were crucial factors to cultivate a learning environment favoring deep learning. ${ }^{5}$ The more the students satisfied the learning environment, the better their academic performance and the more they used deep learning. ${ }^{4}$ Besides, some other factors that might contribute to the adoption of different learning approaches. Students' age, gender, their previous working experience, educational level attained before entering the programme, interest to the programme studied, etc. were found to be associated with the learning approaches eventually adopted. ${ }^{6,7}$

\section{Conclusion}

The significant drop in the mean score of achieving and deep learning approaches in final year students implied that the learning experience in the nursing school might affect their deep understanding of the courses. And the insignificant mean score difference in surface approach seemed an appropriate learning approach for them to 'survive' throughout their study. The findings could be a good piece of evidence to inform nurse educators to review the resource sufficiency of hospital-based training to produce nurses the profession favors.

\section{Acknowledgements}

None.

\section{Conflict of interest}

The author declares no conflict of interest.

\section{References}

1. JB Biggs. Study Process Questionnaire manual: Student approaches to learning and studying. Australian council for educational research. Melbourne, Australia: Springer; 1987

2. SR Snelgrove. Appraoches to learning of student nurses. Nurse Education Today. 2004;24(8):605-614.

3. S. Cowman. The appraoches to learning of student nurses in the Republic of Ireland and Northern Ireland. J Adv Nurs. 1998;28(4):899-910.

4. P Pimparyon, SM Caleer, S Pemba, et al. Educational environment, student approaches to learning and academic achievement in a Thai nursing school. Medical Teacger. 2000;22(4):359-364.

5. GH Rassool, S Rawaf. The influence of learning style preference on undergraduate nursing students on educational outcomes in substance use education. Nurse Educ Pract. 2008;8(5):306-314.

6. M Baeten, E Kyndt, K Struyven, et al. Using student-centred learning environments to stimulate deep approaches to learning: Factors encouraging or discouraging their effectiveness. Educational Research Review. 2010;5(3):243-260.

7. P Mansouri, F Soltani, S Rahemi, et al. Nursing and midwifery students' approaches to study and learning. J Adv Nurs. 2006;54(3):351-358. 